\title{
Correction to: The early warning research on nursing care of stroke patients with intelligent wearable devices under COVID-19
}

\author{
Fengxia $\mathrm{Li}^{1,2} \cdot$ Zhimin $\mathrm{Tao}^{2} \cdot$ Ruiling $\mathrm{Li}^{2} \cdot \mathrm{Zhi} \mathrm{Qu}^{2}$ \\ (C) Springer-Verlag London Ltd., part of Springer Nature 2021
}

\section{Correction to: Palaeobio Palaeoenv}

https://doi.org/10.1007/s00779-021-01520-9

There is a leak in the affiliation information of Fengxia Li (The first author), and the correct affiliation information is "Huaihe Hosipital of Henan University; College of Nursing and Health, Henan University".

Publisher's note Springer Nature remains neutral with regard to jurisdictional claims in published maps and institutional affiliations.

The online version of the original article can be found at https://doi.org/ 10.1007/s00779-021-01520-9

Zhimin Tao

20120028@vip.henu.edu.c

1 Huaihe Hosipital of Henan University, College of Nursing and Health, Henan University, Kaifeng 475001, China

2 College of Nursing and Health, Henan University, Kaifeng 475001, China 